\title{
Comparing the Ethical Code Implementation among Social Workers in Africa: Can Years of Experience Make a Difference?
}

\author{
Nwachukwu, Precious Tobechukwu T.
}

\author{
Department of Social Work, University of Zululand, Private Bag X1001, Kwa-Dlangezwa 3886, South Africa \\ Email: precioustoby@yahoo.com or tobynwachuks@gmail.com
}

\section{Doi:10.5901/mjss.2014.v5n23p2305}

\begin{abstract}
This study investigated attitudinal cognizance on knowledgeability and perceived turbulence among social workers' implementation of Code of Ethics during practice in Africa. Furthermore, the study aimed to find out if years of experience in practice can have significant edge towards ameliorating ethical dilemmas on perceived turbulence or discordancy as well as knowledgeability cognizance of the ethical code in three study areas of Imo and Lagos State, Nigeria and KwaZulu-Natal, South Africa respectively. The quantitative research approach was employed in the use of questionnaire in a survey of social workers (n-135). Data gleaned was analysed by use of descriptive statistics, multiple comparisons and Post Hoc Test. The Findings of the study revealed that while social workers knowledgeability on ethical code application have significantly correlated on years of practice experience, whereas the perceived turbulence ostensibly have limited correlations within the study areas. Moreover, the ethics on integrity of profession, professional responsibility, service delivery and competence/confidentiality account for the integer years of practice experience significant differences in the study. On the basics of the result, it was recommended that arrangements should be established to provide succour to support newer social workers in coping through the mandate and burdens of implementing ethics in practice milieu.
\end{abstract}

Keywords: Code of Ethics, Knowledge score, Turbulence score, Social workers,

\section{Introduction and Background of the Study}

Irrefutably, professional organisations inaugurate code of ethics to premeditate for their functionalities to their practice models. Consequently, the Code of ethics embarks on the clarification of ethical requirements vital to the professional group; creates accountability of the profession and public trust; regulates professional behaviour of practitioners in the organisation, thereby ensuring quality control and expedite sanctions of unethical conducts and applies measures to deal with the detailed violations (Johnson, 1984 cited in Gass, 2009: 1045). The Code of Ethics is an idealistic organisational standards, principles and values that offer expedient procedures for management and professional policymaking; it enthuse disputes between organisational procedures and clients services within the agency. Intrinsically, Wendt, Cheers, Francis, Lonne, and Schiller (2011:1-2) granted that "daily practice settings, interactions and contacts community residents' encounter with social workers might impact on practitioners' views, standards, thoughts, and life experiences, theories" which could influence practice and information sources approved for practice.

The criticisms labelled on the professional code is that they do not offer recipe in addressing conflicts decisions and requirement on appropriate values, principles and standards that has significant impact than others when they conflict with each other (John and Crockwell, 2009; Reamer and Shardlow, 2009). They imprecise about explanation and implication inherent in the principles to be translated into practice; practitioners often do not employ the ethical code during practice and practice is mostly directed by administrative processes and law making the code superfluous (Reamer and Shardlow, 2009; Millstein, 2000; Clark, 1999). Researchers have explicated that practitioners are apt to create choices relying on technical aspects contained by job description than centring it on Code of Ethics' principles and values; only an insignificant figure of practitioners (15.9\%) consulted to the code to solve ethical dilemma; ensuing legal regulation adherence make practitioners to perform incongruity to the code (Kugelman, 1992; Millstein, 2000; Reamer, 2005).

These citations of inquiries in application of the code have been identified, conversely, Reamer and Shardlow (2009) corroborate that the code's "fundamental shift contemporarily, provides resources such as ethical theory with putatively centred decision-making framework, practice theory, research, agency policies, law and regulations; practitioners seek ethically knowledgeable trained persons and regulatory bodies when faced with challenging ethical choices." 
The foremost resolution for this study was perceptibly, appraising the attitudinal cognizance on knowledgeability and perceived turbulence among social workers in their implementation of ethical code during practice within Africa.

\subsection{Rationale for the Study}

This study justification arouse for the support for the inclusion of the principles, values and ethics of National Association of Social Workers (NASW, 2008) complementarily with South African Council of Social Service Practitioners (SACSSP, 2005) ethical code intended in lieu of practitioners. Interchangeably, both codes complement each other toward providing indications that envelope from the ideas that social work profession can be tagged as a technical profession directed via a code of ethics to regulate practice (Banks, 1998). Studies have revealed that the "tone or spirit of the code" lies in examining the "competing values structure" which differentiates a quadrant distinctive differing verbal proportional model, which are informational and instructional; relational and transformational models within the structurally defined communications (Quinn, Hildebrandt, Rogers and Thompson, 1991; Stevens, 1996). They argued that application of the code of ethics within the practice milieu escalates ethical performance anxiety for employees.

Approximately, there is a comparison study on ethical code in illuminating dissimilarities in "historical improvement, procedure, content and structure within professional regulations" between United Kingdom and United States (Reamer and Shardlow, 2009). Similarly, there is a comparison of codes resources outcome within Canadian, Indian, Australian and British codes towards endorsing enhancement of their efficacy on human rights and social justice advocacy (Rodgers, 2009). He advocated the scrutinising of national ethical codes to analyse its efficacy by social workers. On the contrary, there is severe dearth of comparative researches on code of ethics application processes and outcomes amongst African countries.

Furthermore, DiFranks' (2008) study on ethical code implementation within the workplace among social workers found out that "behaviour is compatible with the code" and that supervision is the antidote to curtail stress arising from code's application. Similarly, Tartakorsky and Kovardinaky's (2013) study revealed cognitive-behaviour orientation was linked with greater perception of professional effectiveness. Researchers have investigated relationship between work settings and dilemma-prompted distress (Tartakorsky and Kovardinaky, 2013; Gallina, 2010; John and Crockwell, 2009; DiFranks, 2008; Ulrich, O'Donnell, Taylor, Farrar, Danis \& Crady, 2007).

Therefore, the code has a significant impact to social workers' attitudes and worldview. Social workers were challenged to reconnoitring if the integer "years of experience in practice milieu transmits towards belief, behaviour, discordance, and disjuncture" of the code (DiFranks, 2008:176). However, a study revealed that social workers integer years of service experience enable them to decipher perceptions on causality of crimes from various dimensions not merely on ecological or social dynamics and assist improved understanding on preventive and interventional service schemes (Chui and Chan, 2012:2274).

Consequently, this study is poised to ascertain if years of experience in practice can have a significant edge towards ameliorating ethical dilemmas beliefs on perceived turbulence or discordancy and knowledgeability cognizance of the ethical code.

\section{Literature Review}

Incontrovertibly, studies on NASW Codes of Ethics have dealt with "beliefs around the code, behaviour connected to the code, utilising of the code, evaluating the capability of the code, as well as the code as a guide to professionals, code violations, criticisms of the NASW code, prescriptive ethical decision-making models, suitability of code-prohibited dual relationship, Social Work values entrenched within code, belief in the code and behaviour practical to code and behaviours replicating the creeds within code" (Daley and Hickman, 2011; John and Crockwell, 2009; DiFranks, 2008; Reamer, 2001, 2005; Congress, 2001). Supplementary studies have looked at the affiliation amid problem prompted ethical-strain and practice settings (Gallina, 2010; John and Crockwell, 2009; DiFranks, 2008). Competence of teaching ethics education; techniques utilised in ethics teaching and model of ethical teaching and ethics application to curriculum (Reamer, 2001; Conrad, 1988; Stoesen, 2006).

Farley, Feaster, Schapmire, D'Ambrosio, Bruce, Oak and Sar (2009) attest concerning the utmost repute a social worker's purpose is to offer ethically skilled conveyance of services to clients; they questioned whether social workers recognise if their services are ethically competent, also appropriately preeminent in presenting therapy. Furthermore, a study also discovered that ethics is an essential job tasks required for administrative role. To elucidate, Hoefer, Watson and Preble's (2013:443) analysis of the required job skills of executives from the social work profession within the board chair and the non-profit administrators, they revealed that ethics and integrity were part of the most vital job skills 
participants disclosed that would enable practitioners at that level to perform better in that capacity.

Quinn et al (1991) designed four opposite and competing values, this model when employed to ethical code contributes in perceiving the prevailing tone in the code. Thus, exhibiting the characteristics of the tone within the code, when one dominant verbal element is categorised in each quadrant, it depicts weakness in the opposite one. The purpose is identification of the ethical code's tone which is associated with the objectivity of the code's aims. Therefore, they revealed that the evolving of the ethical code should be based on its implementation, which increases the tension within ethics and performance.

Hoefer et al's (2013) study elucidated that participants verified that effective ethical behaviour, having a workable official guidelines for everyday service, ethical concerns in relationship with clients' system in respect to diverse age groups. Thus, they assert that ethics encompasses the practice goals for managerial effectiveness was some of the reason chosen for the importance of ethics to job skills.

\subsection{Conflict of Ethics within the Practice Milieu}

Ethics programmes are essentially entrenched in organisational culture, yet not overtly advanced (Brenner, 1992), thus, the prerequisite is to establish ethics' workability. Veldsman's study (2012) disclosed four statutorily ethics-performance tensions within the work-place in relation to rightly-ethical application that is ideal and wrongly-ethical application that is unacceptable. He, distinguishes the ideal status 1 , where the employee is an outstanding performer when task is achieved in ethical manner; whereas, in status 2, the employee performs poorly but ethically unswerving. Thus, employees need training to enhance their performance, status 1 and 2 are the right-ethically applied statues. In status 3 , employees achieve their targeted goals at any cost in an unethical manner especially in sales-outcomes; while in status 4, employees perform poorly and unethical which is not desirable, status 3 and 4 are wrong-ethically applied statues and employees in 3 and 4 are detrimental to organisations. Reamer (2013:165) asserts the need for social workers to be conversant with the "digital age of computer proficiency which can influence ethical strain and risk management" within the work-place and the need to protect clients' confidential data at all cost.

Studies have evaluated workers' attitudes and values influence within the human services organisational management, revealed that social workers have higher efficacy as managers as they are immersed with values and individual qualities accruable to the task, proving worthy to greater levels of self-confidence and sensitivity with other professionals than non-social workers (Scannapieco, Hegar, Connell-Carrick, 2012:2172; Moran, Frans and Gibson, 1995; Hopkins, Mudrick and Rudolph, 1999).

A study by Ulrich et al (2007:1713) on social workers and nurses discovered that "one person out of every three participants disclosed strong effect on their level of ethical conflict." Apparently, revealing conflict among professionals within their ethical codes of practice. However, within the Child Protection field, researchers have indicated that interpersonal relationship between social workers and lawyers are more demanding. As a result, social workers are not pertinently cognisant to the legal ethics of lawyers (Vandervort, Gonzalex and Faller, 2007:547). Thus, necessitates that social workers should be conversant about legal ethics to cope during court processes and appearance.

Alluding to Stein (1998) cited in Vandervort et al (2007:548), the incongruities between social workers world view on the future and that of lawyers and judges, indicated that social workers seem to disregard past actions or guidelines, if such were irrelevant to the present situation in agreement within NASW which admonishes practitioners toward becoming changed agents for the beleaguered and deprived in a wider societal inferences. Whereas, the lawyers and judges consult precedent in order to foretell the future actions of situations, as they seek more of the personal rights of clients than that of larger society. Areas of conflict on ethical principles involving these two professional groups on child's welfare include their differences in "definition of client, confidentiality, advocacy, loyalty, objectivity, taking it personally and methods of communication" (Vandervort et al, 2007:554). The clashes of ethical enactment tensions between these two professions have ensured that the field of Child Welfare and Protective Services effect increased turnover among child protection workers (Carnochan et al, 2002 cited in Vandervort et al, 2007).

In comparing nurses and social workers ethical climate, Ulrich et al's study (2007: 172) revealed that ethics in relation to stress and career contentment within demographical variables thru utilising a multivariate analysis, discovered "ethical climate moderately facilitates the association amongst ethical stress and profession fulfilment." They revealed that ethical stress clarifies greatly on the demographics, practice milieu as well as intention-to-stay, as practitioners value being part of the team and accords respect. Furthermore, they revealed that social workers six blocks of demographic variables which are discipline, years in practice, current organisational position, ethical education, ethical climate and ethical stress were indicators for job satisfaction.

However, favourable ethical climate, non-conventional ethical education were contributively factor for enlarged 
work contentment, as social workers with lesser years of practice and those working "full-time showed an intention-toleave" due to augmented ethical stress and unfavourable ethical climate (Ulrich, 2007:1713). Nevertheless, researcher also found no correlations between years in the organisations and retention, also that elevating practitioner to supervisory position could not guarantee their staying in the field of child welfare services (Weaver et al, 2006; Mason, LaPorte, Bronstein and Aurebach, 2012: 1739).

Some studies have found out that organisational factors encourages practitioners' exit from the field, such as lack of supervisory support, promotion openings and salary disparity, derisory preparation on service, "unmet expectations" (Kim, 2011:365; Mason et al, 2012). Further studies have revealed that individual's biographical data such as gender, age, education attainment, conflict of roles, exhaustion and workload have contributed to practitioners leaving the field (Ulrich et al, 2007:1714; Kim, 2011; Shim, 2010).

Kim (2011:364) indicates that genuine career screenings establishes profession prospects or anticipations and practitioner's wiliness to stay-on; meaningfully evolving a "human-caring support" and professional commitment supersedes enacting an emotional arduous duty. Thus, she encouraged social workers to be truthful on their "unmet expectations of work-autonomy, role conflict and administrative support." Similarly, improved organisational commitment correlates with less depersonalisation (Kim and Lee, 2009; Boyas, Wind and Kang, 2012). Thus, forecasting its greater influence on practitioners with more years of practice experience which enables them to cope with the demands of the field and build loyalty to the organisation than less experienced ones.

However, Social work profession in recent times had undergone several processes, fragmentation and increased focus on client's user involvement and consumer rights linking to the notion of the derision on code of ethics applications, but on descriptions of values devoid of discussions with beneficiaries of the offered services. DiFranks (2008:170) discovered that social workers' mean disjuncture scores among various work milieus have significant differences using analysis of variance (ANOVA) to eliminate categories that would contain least numbers of respondents. The outcome indicate that "social workers practising within public organisations incur greatest disjuncture scores, practitioners within private non-profit organisations obtain the least disjuncture scores," in "private non-profits organisations have fewer level of stress than those in public agencies, as managed care accounts for the highest disjuncture scores" (DiFranks, 2008:171-2). Likewise, he revealed that "social workers that are owners of their personal practice have greater level of stress than those in private non-profits and they experience less stress than practitioners in public organisations."

Past studies within substance-abuse field practice experience have suggested that "greater professional efficiency and greater adherence to the psycho-dynamic orientation is related to rational performance positioning of social workers on the code" (Tartakorsky and Kovardinaky, 2013). There is an increasing area of ethical predicament within practice milieu resulting in higher levels of burn-out exhaustion, discordance and cynicism; practitioners most times would override ethical codes for administrative procedures within their organisational policies. Thus, relegating the standards, ideologies and values inherent within code of ethics to mere atomistic implementation as when dimmed fit.

\section{The Present Research}

This study model interest lies contained by combination and encrusting social work practice in the beliefs, principles and values in addressing social workers' belief within tenets in linking the code and their years of experience in practice in the research areas. Hence, this study took into cognizance the existence of biographical details (Age of Participants, Marital Status, Work Setting, Gender, Continuous Professional Development Points Accumulation, Years of Practice Experience and Study Areas) of social workers; the existing management commitment (NASW/SACSSP Code of Ethics) and preferred practice commitment derived from the dominant seven ethical code of choice being applied (Professional responsibility, Competence and Confidentiality, Show care and concern for others, Respect for worth, human rights and dignity of persons, Social justice, Service delivery and Integrity of profession).

Prior measurement on three of the ethical code's components of Respect for worth, human rights and dignity, Social justice; Show care and concern for others well-being amongst the Knowledgeability scores and perceived Turbulence scores, revealed positive significant relationships only in knowledgeability scores. Nevertheless, they show negative correlations in turbulence scores within social workers' years of practice experience.

However, ethics on Service delivery, Integrity of profession, Professional responsibility and Competence/confidentiality had significant differences between Knowledgeability scores and Turbulence scores within the Years of practice experience clued from this study's biological data for social workers, as such, were empirically fitting for this study analysis.

The literature review pertinent indicated that proper planning and academic awareness of the Code of Ethics would prepare social workers being equipped toward incorporating the code in practice. Thus, the stance to survey whether the 
integer years of experience in the practice milieu transmits to perceived turbulence and knowledgeability to social workers' belief and behaviour application of the code.

Hence, the urgent need for the study like this to hypothesised as follows:

- H1: Social workers' perceived knowledgeability on ethical code application (KNWCODESC) is correlated on their integer years of practice experience (INYRSPREX).

- H2: Social workers' perceived turbulence on ethical code application (TUBCODESC) is correlated on their integer years of practice experience (INYRSPREX).

- H3: Social workers' integer years of Practice experience (INYRSPREX) is correlated with their Ethical Code Application at the Practice Areas of the Study (ECODAPRAS).

\section{Research Methods}

This study employed a quantitative descriptive, multiple comparison statistics collaborated by a Post Hoc Test (Brown, 2005:90) of (n-135) social workers at KwaZulu-Natal Province, South Africa; Imo and Lagos States in Nigeria respectively. The selection of participants were expended by a purposeful sample of 258 social workers informed consently drawn from 22 different area agencies-bureaus, which emphases on the choice of respondents pre-eminently epitomised their population and suitable to scrutinised the phenomenon (Patton, 2002; Mason, 1996). Data gleaning utilised a Forty-five detail-series of inquiries that included Likert-like fourteen-item participants' knowledgeable scores and Turbulence scores measurement scale.

The results from prior test-run proved that to a great extent the responses were alike with larger sample attesting the dependability of data that seeks to the strenuous stability of data and over-changing situations (Richter and Mlambo, 2005) to determine the consistency of the obtained data. The estimated distributed questionnaires are at a standard error margin of $10.93 \%$, a confidence level of $90 \%$, and a $52.32 \%$ responded rate. This study utilised the Statistical Programme for Social Sciences (SPSS Version 21.0). Principal Components Analysis (PCA) was used to analyse the data and hypotheses were tested using multiple comparison correlation and Tukey's Post Hoc Test (Brown, 2005) to strengthen the outcome.

\section{Results}

\subsection{Components of KNWCODESC, TUBCODESC, INYRSPREX and ECODAPRAS}

Imperatively, to conceptualise the four scales for this study, the outcomes of Levene's Test for Equality of Variance (LTEV) and T-Test for Equality of Means (T-TEM) independent samples, Analysis of Variance (ANOVA) for the correlation are presented. Additional, the Post Hoc Test for Multiple comparisons correlations was applied and reported. Findings indicated that almost all item ratings fall between mean scores of 1.91 to 3.03 on a 4-point scale (4=Appropriate Knowledge, 3=More Knowledge, 2=Knowledge, 1=Marginal knowledge) for Knowledge Scores; while the Turbulence Scores item ratings fall between mean scores of 1.67 to 1.86 on a 3-point scale (1=Not a Turbulence, $2=$ Minor Turbulence, 3=Major Turbulence). INYRSPREX comprises part of derived biological data of participants, while ECODAPRAS are the study areas of KZN, IMO and LAGOS.

The hypotheses were tested using the Difference between two Proportions and the Difference between Two means; furthermore, the Tukey's Multiple Comparison Post Hoc Test (Brown, 2005) analysis was used when the null hypothesis $\left(\mathrm{H}_{0}\right)$ is rejected, thus all measurement were tested at a significance level of $p<0.05$. To derive the knowledge scores and turbulence scores for the section $\mathrm{C}$ of the questionnaire, that had a closed-ended pattern for social workers in this study, an indicator variable for each ethical component was derived by the scores that were calculated as an average of the ratings given under each of the categories; one for knowledge and the other for turbulence. 


\subsection{Perception of Knowledgeability of Ethical Code}

Table 1: Independent Sample Test LTEV and T-TEM for perceptions in comparison of Knowledge scores and Turbulence scores for Social workers among the Provinces/States

Independent Samples Test

\begin{tabular}{|l|c|c|c|c|c|}
\hline \multirow{2}{*}{} & \multicolumn{3}{|c|}{ Levene's Test for Equality of Variances } & \multicolumn{3}{|c|}{ t-test for Equality of Means } \\
\cline { 2 - 6 } & $\mathrm{F}$ & Sig. & $\mathrm{t}$ & $\mathrm{df}$ & Sig. (2-tailed) \\
\hline \multirow{2}{*}{ Knowledge Score } & .014 & .908 & -.072 & 133 & .942 \\
& & & -.070 & 45.245 & .944 \\
Turbulence Score & .152 & .697 & .229 & 133 & .819 \\
& & & .219 & 43.906 & .828 \\
\hline
\end{tabular}

Table 1 reports the result of the Independent Samples Test of Levene's Test for Equality of Variances and T-test for Equality of Means (Sig.2-tailed) and the Descriptives of the Knowledge Scores and Turbulence Scores amid Provinces measurement scales; Levene's Test for Equality of Variances showed that Knowledge Score for frequency derivatives with the perception of knowledgeability on ethical code and integer years of practice experience; and the Levene's Test for Equality of Variances of the Turbulence Score for frequency derivatives had no correlations.

Table 2: ANOVA Test for Knowledge Scores between Groups and within Groups for Social Workers

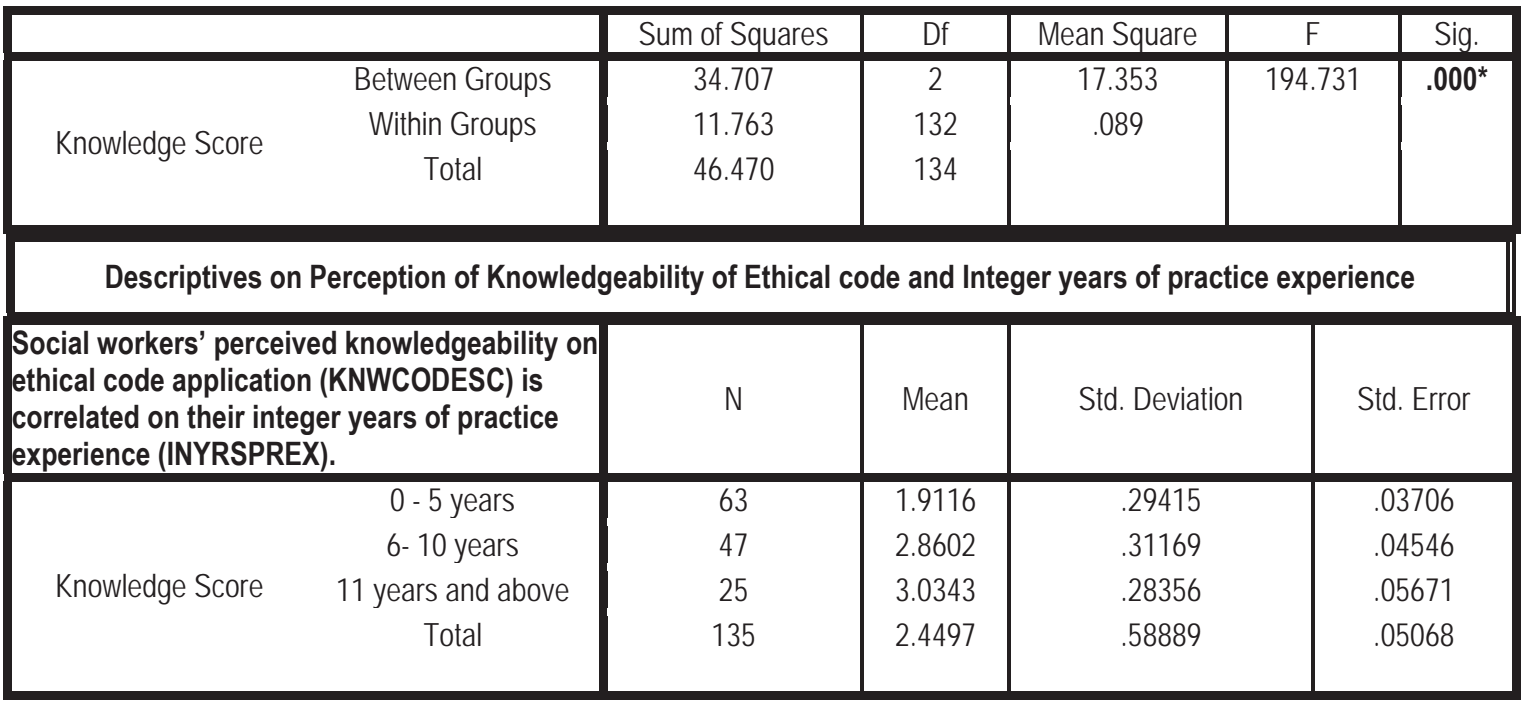

${ }^{*}$ Correlation is significant at the 0.05 level (2-tailed)

Table 2 reports the result of the ANOVA Test of the Knowledge Scores and Integer years of practice measurement scales between and within Groups; Social workers' perceived knowledgeability on ethical code application (KNWCODESC) is correlated on their integer years of practice experience (INYRSPREX).

Therefore, H1: Social workers' perceived knowledgeability on ethical code application (KNWCODESC) is correlated on their integer years of practice experience (INYRSPREX) is accepted. DiFranks' study (2008:170) discloses that there is a moderate significant amongst "disjuncture and discordant belief and behaviour scores at a significant level of .05 , if the disjuncture scores stayed definitely related through discordance of belief and behaviour scores."

The ANOVA Test (DiFranks, 2008) was applied, he employed the analysis of variance (ANOVA) to eliminate categories that would contain least numbers of respondents and found out that social workers' mean disjuncture scores within several work-milieus have correlations. For the integer years of practice experience, the mean and standard deviation for this study, demonstrated that social workers with 0-5years of practice experience had the least mean knowledge score of (1.9116), in comparison with practitioners with 6-10 years of practice experience that are higher (2.8602). Furthermore, social workers with 11 years-above in practice experience had the highest mean KNWCODESC (3.0343). 
This revealed that social workers with more integer years of practice experience have greater perception on knowledgeability of application of the code in the study areas. DiFranks (2008) found out that social workers' mean disjuncture scores among various work milieus have significant differences using analysis of variance (ANOVA) to eliminate categories that would contain least numbers of respondents.

\subsection{Perception of Turbulence on Ethical Code}

Table 3: Descriptives on Perception of Turbulence of ethical code and integer years of practice experience

\begin{tabular}{|c|c|c|c|c|c|}
\hline $\begin{array}{l}\text { Social workers' perceived turbulence on ethical code application } \\
\text { (TUBCODESC) is correlated on their integer years of practice experience } \\
\text { (INYRSPREX). }\end{array}$ & $\mathrm{N}$ & Mean & \multicolumn{2}{|c|}{ Std. Deviation } & $\begin{array}{l}\text { Std. } \\
\text { Error }\end{array}$ \\
\hline $\begin{array}{c}0-5 \text { years } \\
6-10 \text { years } \\
11 \text { years and above } \\
\text { Total }\end{array}$ & $\begin{array}{c}63 \\
47 \\
25 \\
135\end{array}$ & $\begin{array}{l}1.78912 \\
1.77812 \\
1.66857 \\
1.76296\end{array}$ & \multicolumn{2}{|c|}{$\begin{array}{l}.214450 \\
.234187 \\
.235895 \\
.228333\end{array}$} & $\begin{array}{l}.027018 \\
.034160 \\
.047179 \\
.019652 \\
\end{array}$ \\
\hline \multicolumn{6}{|c|}{ ANOVA Test for Scores between Groups and within Groups for Social Workers } \\
\hline & $\begin{array}{l}\text { Sum of } \\
\text { Squares }\end{array}$ & Df & $\begin{array}{c}\text { Mean } \\
\text { Square }\end{array}$ & $\mathrm{F}$ & Sig. \\
\hline $\begin{array}{l}\text { Between Groups } \\
\text { Within Groups } \\
\text { Total }\end{array}$ & $\begin{array}{l}.277 \\
6.710 \\
6.986\end{array}$ & $\begin{array}{c}2 \\
132 \\
134\end{array}$ & $\begin{array}{l}.138 \\
.051\end{array}$ & 2.721 & .069 \\
\hline
\end{tabular}

**The mean difference is not significant at the 0.05 level

Table 3 displays the result of the Descriptives and ANOVA Test of the Turbulence Scores and Integer years of practice measurement scales; Social workers' perceived Turbulence on ethical code application (TUBCODESC) has no correlations on their integer years of practice experience (INYRSPREX). Although DiFranks' study revealed that social workers' mean disjuncture scores among various work milieus have significant differences using analysis of variance (ANOVA) to eliminate categories that would contain least numbers of respondents, in this study showed no correlations.

However, for the integer years of practice experience, the mean and standard deviation show that social workers with 0-5years of practice experience had the highest mean Turbulence score of (1.78912), in comparison with practitioners with 6-10 years of practice experience that are lower turbulence score (1.77812). Furthermore, social workers with 11 years and above in practice experience had the lowest mean turbulence score (1.66857). This revealed that social workers with lesser integer years of practice experience have greater perceptiveness on turbulence of application of the code in the study areas.

This study finding correlates with other studies those social workers with lesser years of practice indicated "intention-to-leave" because of augmented ethical stress and unfavourable ethical climate, "unmet expectations of task, role conflict and lack of administrative support (Ulrich et al, 2007:1713; Kim, 2011:364). 
Table 4: Post Hoc Tests on KNWCODESC and TUBCODESC for Social Workers

\begin{tabular}{|c|c|c|c|c|c|}
\hline \multicolumn{6}{|c|}{ Multiple Comparisons LSD } \\
\hline Dependent Variable & (I) years of Exp. & (J) years of Exp. & Mean Difference (I-J) & Std. Error & Sig. \\
\hline \multirow{8}{*}{ Knowledge Score } & \multirow{2}{*}{0 - 5 years } & 6- 10 years & $-.94862^{*}$ & .05754 & .000 \\
\hline & & 11 years and above & $-1.12272^{*}$ & .07056 & .000 \\
\hline & \multirow{2}{*}{$6-10$ years } & $0-5$ years & $.94862^{*}$ & .05754 & .000 \\
\hline & & 11 years and above & $-.17410^{*}$ & .07390 & .020 \\
\hline & \multirow{2}{*}{11 years and above } & 0 - 5 years & $1.12272^{*}$ & .07056 & .000 \\
\hline & & $6-10$ years & $.17410^{*}$ & .07390 & .020 \\
\hline & 0 - 5 vears & $6-10$ years & .011000 & .043455 & .801 \\
\hline & 0 - years & 11 years and above & $.120544^{*}$ & .053292 & .025 \\
\hline \multirow{4}{*}{ Turbulence Score } & \multirow{2}{*}{$6-10$ years } & $0-5$ years & -.011000 & .043455 & .801 \\
\hline & & 11 years and above & .109544 & .055810 & .052 \\
\hline & \multirow{2}{*}{11 years and above } & 0 - 5 years & $-.120544^{*}$ & .053292 & .025 \\
\hline & & $6-10$ years & -.109544 & .055810 & .052 \\
\hline
\end{tabular}

${ }^{\star \star}$ The mean difference is significant at the 0.05 level

Table 4 shows result of the Tukey's Multiple Comparison Post Hoc Test for KNWCODESC and TUBCODESC which depicts the correlations of multiple comparisons (Ulrich et al, 2007) within the Integer years of experience. However, to strengthen the hypotheses results in comparison of $\mathrm{H} 1$ and $\mathrm{H} 2$ showed significant differences, if both were rejected there would have been no need for the Post Hoc analysis. Therefore, the Post Hoc test was applied which portrays that the means scores had correlations.

KNWCODESC has correlation with INYRSPREX among 6-10years (.020) which is <.05 in comparison with 11 years and above; while $0-5$ years had $(.000)<.05$ for both comparison for 6-10years and 11 years-above in all the observed variables. Social workers with $0-5$ years has lesser KNWCODESC (-.94863) in comparison with 6-10 years; likewise (-1.12272) to 11 years and above. Social workers with 6-10 years (-.17410) has lower KNWCODESC compared to 11 years-above. This further strengthened the ANOVA results in Table 2.

Furthermore, TUBCODESC has correlations with INYRSPREX among 0-5 years (.025) in comparison with 11 years and above. Social workers with $0-5$ years have greater TUBCODESC (.120544) in comparison with practitioners with 11 years- above, thus strengthening the results at Table 3 that more integer years of practice experience assist in perceived coping with turbulence on code application.

\subsection{Determinants of Attitudinal cognizance of Social workers to Ethical code Application in Provinces (study areas)}

Table 5 : Descriptives statistics for Mean and Standard Deviation among Provinces of the study

\begin{tabular}{|c|c|c|c|c|c|}
\hline \multicolumn{2}{|c|}{$\begin{array}{l}\text { Social workers' integer years of Practice experience (INYRSPREX) and Ethical } \\
\text { Code application at the Practice Areas of the Study (ECODAPRAS). }\end{array}$} & $\mathrm{N}$ & Mean & $\begin{array}{l}\text { Std. } \\
\text { Deviation }\end{array}$ & $\begin{array}{l}\text { Std. } \\
\text { Error }\end{array}$ \\
\hline \multirow{4}{*}{ Knowledge Score } & KZN & 92 & 2.3991 & .60407 & .06298 \\
\hline & LAGOS & 10 & 2.6571 & .64312 & .20337 \\
\hline & IMO & 33 & 2.5281 & .52060 & .09063 \\
\hline & Total & 135 & 2.4497 & .58889 & .05068 \\
\hline \multirow{4}{*}{ Turbulence Score } & KZN & 92 & 1.72360 & .234695 & .024469 \\
\hline & LAGOS & 10 & 1.80000 & .167684 & .053026 \\
\hline & IMO & 33 & 1.86147 & 197190 & .034326 \\
\hline & Total & 135 & 1.76296 & .228333 & .019652 \\
\hline
\end{tabular}

Table 5 reports the result of the Descriptives of the Knowledge Scores and Turbulence Scores among Provinces 
measurement scales; Social workers' integer years of Practice experience (INYRSPREX) and Ethical Code Application at the Practice Areas of the study (ECODAPRAS). In the provinces, the mean and standard deviation show that KZN has least mean knowledge score of (2.3991) compared to IMO (2.6571) and LAGOS (2.5281). In problem score, KZN has least KNWCODESC of (1.72360) compared to IMO (1.86147) and LAGOS (1.8000).

This implies that for social workers in this study, KZN has the least perceived knowledgeability score to the Code of Ethics than their counterparts at LAGOS and IMO. However, in the perception of TUBCODESC, KZN has least degree turbulence than LAGOS and IMO. IMO has the greater perceived TUBCODESC for social workers followed by LAGOS.

Table 6: ANOVA Correlations between INYRSPREX, KNWCODESC, TUBCODESC and ECODAPRAS

\begin{tabular}{|c|c|c|c|c|c|}
\hline INYRSPREX and ECODAPRAS & Sum of Squares & $\mathrm{df}$ & Mean Square & $\mathrm{F}$ & Sig. \\
\hline & .869 & 2 & .435 & 1.258 & .288 \\
Knowledge Score & 45.601 & 132 & .345 & & \\
& 46.470 & 134 & & \\
Turbulence Score & .476 & 2 & .238 & 4.831 & $* .009$ \\
& 6.510 & 132 & .049 & & \\
\hline
\end{tabular}

* Correlation is significant at the 0.05 level (2-tailed).

Table 6 indicates the Analysis of Variance (ANOVA) correlations of the Knowledge Scores and Turbulence Scores amid Provinces measurement scales; Social workers' integer years of Practice experience (INYRSPREX) and Ethical Code Application at the Practice Areas of the study (ECODAPRAS).

H3: Social workers' integer years of Practice experience (INYRSPREX) is correlated with their Ethical Code Application at the Practice Areas of the Study (ECODAPRAS). At least the mean scores are different from others as the turbulence scores showed a significant difference of (.009) which is <.05 when compared with the knowledge scores of (.288) which is $>.05$. At least one of the locations has a higher mean TUBCODESC and KNWCODESC for social workers at KZN, LAGOS and IMO are different is thereby accepted.

The means in bold are significantly different for instance, the mean turbulence scores for KZN is significant higher that of IMO. If the H3 was rejected there would have been no need for the Post Hoc analysis. Therefore, the Tukey's Post Hoc test was applied which portrays that means scores were slightly difference.

Table 7: Post Hoc Tests Multiple Comparison Correlations between INYRSPREX, KNWCODESC, TUBCODESC and ECODAPRAS

\begin{tabular}{|c|c|c|c|c|c|}
\hline Dependent Variable & (I) STATE & (J) STATE & Mean Difference (I-J) & Std. Error & Sig. \\
\hline \multirow{6}{*}{ Knowledge Score } & \multirow{2}{*}{ KZN } & LAGOS & -.25807 & 19571 & .190 \\
\hline & & IMO & -.12907 & . 11926 & .281 \\
\hline & \multirow{2}{*}{ LAGOS } & KZN & 25807 & 19571 & 190 \\
\hline & & IMO & 12900 & 21217 & .544 \\
\hline & \multirow{2}{*}{ IMO } & KZN & . 12907 & . 11926 & 281 \\
\hline & & LAGOS & -.12900 & .21217 & .544 \\
\hline \multirow{6}{*}{ Turbulence Score } & \multirow{2}{*}{ KZN } & LAGOS & -.076398 & .073944 & .303 \\
\hline & & IMO & -.137869* & 045061 & $.003^{*}$ \\
\hline & \multirow{2}{*}{ LAGOS } & KZN & .076398 & .073944 & .303 \\
\hline & & IMO & - .061472 & .080163 & .445 \\
\hline & \multirow{2}{*}{ IMO } & KZN & $.137869^{*}$ & .045061 & $.003^{*}$ \\
\hline & & LAGOS & .061472 & . 080163 & .445 \\
\hline
\end{tabular}

**The mean difference is significant at the 0.05 level

Table 7 depicts the Post Hoc Tests of Tukey's multiple comparison correlations between INYRSPREX, KNWCODESC, 
TUBCODESC and ECODAPRAS. The sum total means in TUBCODESC showed that in comparison between KZN and IMO there is a significant difference (.003), the mean knowledge and turbulence scores are different.

Therefore, the H3, which stated: Social workers' integer years of Practice experience (INYRSPREX) is correlated with their Ethical Code Application at the Practice Areas of the Study (ECODAPRAS) is accepted. In comparison on the TUBCODESC, the mean difference for KZN (-.137869) is lower than IMO (.137869) and LAGOS (.076398) which implies that social workers at KZN experience less turbulence in application of the NASW/SACSSP Code of Ethics.

Table 8: INYRSPREX, KNWCODESC, TUBCODESC and NASWISACSSP Code of Ethics Outcomes

\begin{tabular}{|c|c|c|c|c|c|c|}
\hline \multirow{3}{*}{$\begin{array}{c}\text { Knowledge and } \\
\text { problem variables }\end{array}$} & \multicolumn{6}{|c|}{ SOCIAL WORKERS } \\
\hline & \multicolumn{3}{|c|}{ RESPWORHUMRIGTHS } & \multicolumn{3}{|c|}{ PROFESSIONAL RESPONSIBILITY } \\
\hline & $0-5 y r s$ & 6-10yrs & 11+yrs & $0-5 y r s$ & 6-10yrs & $11+y r s$ \\
\hline Marginal know & $7 a(11.1 \%$ & $0_{b}(0.0 \%$ & $2 \mathrm{a}(8.0 \%$ & $55 a(87.3 \%$ & $6_{b}(12.8 \%$ & $2 b(8.0 \%$ \\
\hline Knowledgeable & $23 a(36.5 \%$ & $6_{b}(12.8 \%$ & $3 \mathrm{~b}(12.0 \%$ & $6 \mathrm{a}(9.5 \%$ & $25_{b}(53.2 \%$ & $8 \mathrm{~b}(32.0 \%$ \\
\hline More knowledge & $19 \mathrm{a}(30.2 \%$ & $10 \mathrm{a}(21.3 \%$ & $4 a(16.0 \%$ & $2 \mathrm{a}(3.2 \%$ & $9_{b}(19.15$ & $12 c(48.0 \%$ \\
\hline Appr. Knowledge & $14 \mathrm{a}(22.2 \%$ & $31_{b}(66.0 \%$ & $16_{b}(64.0 \%$ & $0 \mathrm{a}(0.0 \%$ & $7_{b}(14.9 \%$ & $3 b(12.0 \%$ \\
\hline Total & $63(100.0 \%$ & $47(100.0 \%$ & $25(100.0 \%$ & $63(100.0 \%$ & $47(100.0 \%$ & $25(100.0 \%$ \\
\hline Not a problem & $37 a(58.7 \%$ & $24 \mathrm{a}(51.1 \%$ & $9 \mathrm{a}(36.0 \%$ & $21 \mathrm{a}(33.3 \%$ & $12 \mathrm{a}(25.5 \%$ & $10 \mathrm{a}(40.0 \%$ \\
\hline Minor problem & $11 \mathrm{a}(17.5 \%$ & $6 \mathrm{a}(12.8 \%$ & $5 a(20.0 \%$ & $33 a(52.4 \%$ & $15_{b}(31.9 \%$ & $4 b(16.0 \%$ \\
\hline Major problem & $15 \mathrm{a}(23.8 \%$ & $17 \mathrm{a}(36.2 \%$ & $11 \mathrm{a}(44.0 \%$ & $9 \mathrm{a}(14.3 \%$ & $20_{b}(42.6 \%$ & $11_{b}(44.0 \%$ \\
\hline \multirow[t]{2}{*}{ Total } & $63(100.0 \%$ & $47(100.0 \%$ & $25(100.0 \%$ & $63(100.0 \%$ & $47(100.0 \%$ & $25(100.0 \%$ \\
\hline & \multicolumn{3}{|c|}{ COMPETENCE/CONFIDENTIAL } & \multicolumn{3}{|c|}{ SOCIAL JUSTICE } \\
\hline Marginal know & $55 \mathrm{a}(87.3 \%$ & $7_{\mathrm{b}}(14.9 \%$ & $4 b(16.0 \%$ & $2 \mathrm{a}(3.2 \%$ & $0 \mathrm{a}(0.0 \%$ & $0 \mathrm{a}(0.0 \%$ \\
\hline Knowledgeable & $4 \mathrm{a}(6.3 \%$ & $27 \mathrm{~b}(57.4 \%$ & $13_{b}(52.0 \%$ & $26 \mathrm{a}(41.3 \%$ & $2 \mathrm{~b}(4.3 \%$ & $1_{b}(4.0 \%$ \\
\hline More knowledge & $4 \mathrm{a}(6.3 \%$ & $8 \mathrm{a}(17.0 \%$ & $4 \mathrm{a}(16.0 \%$ & $32 \mathrm{a}(50.8 \%$ & $12_{b}(25.5 \%$ & $\sigma_{b}(24.0 \%$ \\
\hline Appr. Knowledge & $0 \mathrm{a}(0.0 \%$ & $5 b(10.6 \%$ & $4 b(16.0 \%$ & $3 \mathrm{a}(4.8 \%$ & $33_{b}(70.2 \%$ & $18 \mathrm{~b}(72.0 \%$ \\
\hline Total & $63(100.0 \%$ & $47(100.0 \%$ & $25(100.0 \%$ & $63(100.0 \%$ & $47(100.0 \%$ & $25(100.0 \%$ \\
\hline Not a problem & $5 \mathrm{a}(7.9 \%$ & $12 \mathrm{~b}(25.5 \%$ & $16 c(64.0 \%$ & $39 a(61.9 \%$ & $22(46.8 \%$ & $12 \mathrm{a}(48.0 \%$ \\
\hline Minor problem & $7 a(11.15 \%$ & $12 \mathrm{~b}(25.5 \%$ & $5 a, b(20.0 \%$ & $9 \mathrm{a}(14.3 \%$ & $12 \mathrm{a}(25.5 \%$ & $3 a(12.0 \%$ \\
\hline Major problem & $51 \mathrm{a}(81.0 \%$ & $23 \mathrm{~b}(48.9 \%$ & $4 c(16.0 \%$ & $15 \mathrm{a}(23.8 \%$ & $13 \mathrm{a}(27.7 \%$ & $10 \mathrm{a}(40.0 \%$ \\
\hline Total & $63(100.0 \%$ & $47(100.0 \%$ & $25(100.0 \%$ & $63(100.0 \%$ & $47(100.0 \%$ & $25(100.0 \%$ \\
\hline \multicolumn{4}{|c|}{$\begin{array}{c}\text { INTEGRITY OF PROFESSION } \\
\end{array}$} & \multicolumn{3}{|c|}{ SHOW CONCERN } \\
\hline Marginal know & $59 \mathrm{a}(93.7 \%$ & $20_{b}(42.6 \%$ & $1 \mathrm{c}(4.0 \%$ & $8 a(12.7 \%$ & $0_{b}(0.0 \%$ & $0_{a, b}(0.0 \%$ \\
\hline Knowledgeable & $4 \mathrm{a}(6.3 \%$ & $19 \mathrm{~b}(40.0 \%$ & $16_{b}(64.0 \%$ & $37 a(58.7 \%$ & $8 b(17.0 \%$ & $3 b(12.0 \%$ \\
\hline More knowledge & $0 \mathrm{a}(0.0 \%$ & $6_{b}(12.8 \%$ & $6_{b}(24.0 \%$ & $17 \mathrm{a}(27.0 \%$ & $20 \mathrm{a}, \mathrm{b}(42.6 \%$ & $13_{b}(52.0 \%$ \\
\hline Appr. knoweldge & $0 \mathrm{a}(0.0 \%$ & $2 \mathrm{a}, \mathrm{b}(4.3 \%$ & $2 \mathrm{~b}(8.0 \%$ & $1 \mathrm{a}(1.6 \%$ & $19 \mathrm{~b}(40.4 \%$ & $9 \mathrm{~b}(36.0 \%$ \\
\hline Total & $63(100.0 \%$ & $47(100.0 \%$ & $25(100.0 \%$ & $63(100.0 \%$ & $47(100.0 \%$ & $25(100.0 \%$ \\
\hline Not a problem & $28 \mathrm{a}(44.4 \%)$ & $32 \mathrm{~b}(68.1 \%$ & $21_{b}(84.0 \%$ & $51 \mathrm{a}(81.0 \%$ & $33 a(70.2 \%$ & $16 \mathrm{a}(64.0 \%$ \\
\hline Minor problem & $29 \mathrm{a}(46.0 \%$ & $13_{b}(27.7 \%$ & $4 b(16.0 \%$ & $12 \mathrm{a}(19.0 \%$ & $13 \mathrm{a}(27.7 \%$ & $8 \mathrm{a}(32.0 \%$ \\
\hline Major problem & $6 \mathrm{a}(9.5 \%$ & $2 \mathrm{a}(4.3 \%$ & $0 \mathrm{a}(0.0 \%$ & $0 \mathrm{a}(0.0 \%$ & $1 \mathrm{a}(2.1 \%$ & $1 \mathrm{a}(4.0 \%$ \\
\hline Total & $63(100.0 \%$ & $47(100.0 \%$ & $25(100.0 \%$ & $63(100.0 \%$ & $47(100.0 \%$ & $25(100.0 \%$ \\
\hline \multicolumn{4}{|c|}{ SERVICE DELIVERY } & \multirow{9}{*}{\multicolumn{3}{|c|}{$\begin{array}{l}{ }^{* *} \text { The mean difference is significant at the } 0.05 \\
\text { level: Figures in bolded form have statistical } \\
\text { differences. }\end{array}$}} \\
\hline Marginal know & $5 \mathrm{a}(7.9 \%$ & $0_{b}(0.0 \%$ & $0,0, b=0$ & & & \\
\hline Knowledgeable & $26 \mathrm{a}(41.3 \%$ & $7_{b}(14.9 \%$ & $2 b(8.0 \%$ & & & \\
\hline More knowledge & $22_{a, b}(34.9 \%$ & $23_{b}(48.9 \%$ & $5 a(20.0 \%$ & & & \\
\hline Appr. knoweldge & $10 \mathrm{a}(15.9 \%$ & $17_{b}(36.2 \%$ & $18 \mathrm{c}(72.0 \%$ & & & \\
\hline Total & $63(100.0 \%$ & $47(100.0 \%$ & $25(100.0 \%$ & & & \\
\hline Not a problem & $23 a(36.5 \%$ & $24_{a, b}(51.1$ & $15 \mathrm{~b}(60.0 \%$ & & & \\
\hline Minor problem & $25 \mathrm{a}(39.7 \%$ & $13 \mathrm{a}(27.7 \%$ & $6 a(24.0 \%$ & & & \\
\hline Major problem & $15 \mathrm{a}(23.8 \%$ & $10 \mathrm{a}(21.3 \%$ & $4 \mathrm{a}(16.0 \%$ & & & \\
\hline Total & $63(100.0 \%$ & $47(100.0 \%$ & $25(100.0 \%$ & & & \\
\hline
\end{tabular}

Table 8 results indicates the INYRSPREX, KNWCODESC, TUBCODESC and NASWISACSSP Code of Ethics Outcomes; on Respect for Worth of person, Human rights and Dignity (RWHRDGT), Social Justice and Show Concern ethics had correlation on KNWCODESC but no significant correlations on TUBCODESC within social workers' Years of Experience. Thus, they were not apt for the further analysis, whereas, ethics on Professional responsibility, Integrity of 
profession, Competence/Confidentiality and Service delivery all had significant correlations between KNWCODESC and TUBCODESC were reckoned for analysis.

For Professional responsibility on KNWCODESC and INYRSPREX, there were correlations among social workers with 6-10years and those with 11years-above within marginal knowledge, knowledgeable, more knowledge and appropriate knowledge. In TUBCODESC and INYRSPREX, there were correlations between social workers with 610years and 11years- above on minor and major turbulence scores; $44.0 \%$ perceived it to be a major turbulence for 11years above, while $42.6 \%$ view it as major problem for 6-10years. However, social workers with 0-5years on KNWCODESC has a marginal knowledge of $87.3 \%$; whereas on TUBCODESC has $14.3 \%$ to perception of professional responsibility within INYRSPREX.

For the ethic Integrity of profession on KNWCODESC and INYRSPREX, there were correlations between 610years and 11years-above on marginal, knowledgeable, more knowledge and appropriate knowledge, while social workers with 0-5years revealed a marginal knowledge of 93.7\%. In TUBCODESC and INYRSPREX, there were correlations between 6-10years and 11years-above on not a problem score of $68.1 \%$ and $84.0 \%$ respectively and minor problem scores, nevertheless, there were low ratings across the respective years of experience for integrity of profession as a major problem score.

The ethic of Competence and Confidentiality for TUBCODESC and INYRSPREX depict social workers 0-5years perceiving it as a major turbulence with $81.0 \%$, also 6-10years has a relative view with $48.9 \%$. There were significant correlations between 6-10years and 11years-above on not a problem, minor and major problem scores. In KNWCODESC and INYRSPREX, depicted correlations between 11years-above and 6-10years in all the knowledgeable scores therein.

The Service delivery ethic for TUBCODESC and INYRSPREX reveals correlations between 6-10years and 11years-above as both recorded $51.1 \%$ and $60.0 \%$ respectively to the ethic as not a perceived problem. However, for KNWCODESC and INYRSPREX, there were correlations between 0-5years and 6-10years for more knowledge score, whereas, 6-10years and 11years-above had correlations for marginal, knowledgeable and appropriate knowledge scores.

\section{Discussions}

Generally, social workers with 6-10years and 11years-above had higher ratings scores on KNWCODESC's appropriate knowledge for ethics: Respect for worth, human rights and dignity (RESPWORHUMRIGTHS), Social justice, Show concern and care for others, Service delivery in comparison to 0-5 years that had lower rating scores across these ethics. Interestingly, there were lower rating scores for KNWCODESC's appropriate knowledge for ethics: Competency, Professional responsibility and Integrity of profession, however, social workers with 0-5 years had lower rating scores for KNWCODESC's appropriate knowledge transversely virtually all the ethics.

In appraising their TUBCODESC major turbulence for ethic social justice had $40.0 \%$ for 11 years-above and $44.0 \%$ for ethic respect for worth, human rights and dignity, while 6-10years had higher major score perceptions on ethics of competence and respect for worth, human rights and dignity. This finding depicts the severity of the challenges facing the profession in uplifting the training of practitioners on ethics building and utilisation during practice. The study findings correlates with John and Crockwell (2009) that the code provides the supportive guidance, information in challenging also to balance organisational policies and ethical responsibility.

DiFranks' study (2008: 170) analysed "behaviour and disjuncture had negative correlation of .45 which is tested at significant level of .05 ," that greater significant correlation recorded amongst "behaviour scores and disjuncture scores yields negative correlations" showing that behaviour that is extremely consistent with the code results in low disjuncture, while behaviour outside the code produces high disjuncture."

This study findings, social workers that have lesser years of practice experience had greater perceived TUBCODESC than those with more experience correlates with Kim and Lee (2009) and Boyas et al (2012) studies implying practitioners with more years of experience aligned themselves to greater organisational commitment which assist them to be less depersonalisation, thereby, enables them to cope with the demand on the field and build loyalty to their organisations than those with less years of experience.

In addition, Ulrich et al's (2007:1715) study revealed that social workers had higher scores on ethical climate questions than resident-nurses and increased work fulfilment at 95\% significant to the model for intent-to-leave. This finding reinforces that social workers that had "not received ethics education and less ethical stress and ethical climate" are predicators for job fulfilment (Ulrich et al, 2007:1714). Thus, improvement on ethical climate and stress through consultations with proper supervision contributively influence for justifiable motive for intention-to stay.

Further, it clarifies that social workers would prefer to practice within the confinements of Code of Ethics and effective communication contrivance that result to satisfaction and professional enhancement. Studies have linked 
effective communication, inclusion of workers in decision making and increased perception of fairness to an intention-tostay (Kim and Lee, 2009; Mor Barak et al, 2006). Furthermore, Wendt et al (2011:2) asserted that administrators should look inwards to this concern and identify the impact and adopt coping mechanism to guide practitioners; supervisors and executives should engage in further arrangement for ethical training (John and Crockwell, 2009). Thus, the establishing of interventional structures to assist fresher personnel to tackle pressures and stresses (Boyas, Wind and Kang, 2012). However, less experienced social workers should be assisted to stay on in the field with supportive supervision and communication inclusive network which reinforces career progress (Boyas and Wind, 2010; Mor Barak et al, 2006).

\subsection{Limitations and recommendation for further study}

The present study has some limitations, as a solitary quantitative study, there is need for an in-depth interview perceptives on the ratings on the ethics that were measured, likewise, the estimable of parity within government and nonprofit organisations. This comparison should contribute in assessing the extent of the knowledgeability and turbulence scores impact on the perceived interpretations of code of ethics as it affects integer years of experience. The $52 \%$ rate of respondents' evaluations can be envisaged as not getting the maximum attributes to the responses.

Furthermore, one might not rule out the greater number of respondents from KZN compared to IMO and LAGOS that could have an impacted on the result, but empirically social workers in Nigeria during deliberations which were not included in this study have experience more perceived turbulence in application of the code in this study.

In summary, there is need for identification and implementable conversant practitioners having a workable guidelines and achievable right-ethical task mannered social workers (Quinn et al, 1991; Hoefer et al, 2013; Veldsman, 2012). Implementing ethical code during practice and as a way of life evolves ethically competent social workers, stimulates task conveyed professionally with ethical manner and the improvement of task poorly conveyed but ethically interwoven. Social workers involved in the latter job assignment should be commended for including ethical mind-set into practice for effective and efficient practice conveyance.

Further studies should geared toward "behaviour, discordance, and disjuncture" (DiFranks, 2008) of the code by social workers and administrators perceptions on KNWCODESC and TUBCODESC within INYRSPREX. Research should look into the role of administrators within the organisations to ascertain implementation of ethical code by social workers, ascertain the mechanisms put in place to have right-ethical application achievability on task for susceptible practitioners.

\section{References}

Banks, S. (1998). Professional Ethics in Social Work-What Future? British Journal of Social Work 28: 213-231.

Boyas, J. F., Wind, L. H. \& Kang, S-Y. (2012). Exploring the relationship between employment -based social capital, job stress, burnout, and intent to leave among child protection workers: An age-based path analysis model. Children and Youth Services Review, 34:50-62.

Brenner, S. N. (1992). Ethics Programmes and their Dimensions. Journal of Business Ethics, 11:391-399.

Brown, A. M. (2005). A new software for carrying out one-way ANOVA post hoc tests. Computer Methods and Programs in Biomedicine, 79:89-95.

Chui, W. H., \& Chan, H. C (0). (2012). Outreach social workers for at-risk youth: A test of their attitudes towards crime and young offenders in Hong Kong. Children and Youth Services Review, 34:2273-2279.

Clark, C. (1999). Observing the lighthouse: From theory to institution in Social Work Ethics. European Journal of Social Work, 2 (3):259270.

Code of Ethics of the National Association of Social Workers (2008). Approved by the 1996 NASW Delegate Assembly and revised by the 2008 NASW Delegate Assembly. Available at http://www.socialworkers.org/pubs/code/code.asp [Retrieved on 24/06/2012].

Congress, E. (2001). Dual relationships in Social Work education: Report on a National Survey. Journal of Social Work Education, 37:12.

Conrad, A. (1988). Ethical considerations in the psychosocial process. Social Casework, 69:603- 610.

DiFranks, N. N. (2008). Social Workers and the NASW Code of Ethics: Belief, Behaviour, Disjuncture. Social Work, 53(2): 167-176.

Farley, A. J., Feaster, D., Schapmire, T. J., D’Ambrosio, J. G., Bruce, L. E., Oak, C. S. \& Sar, B. K. (2009). The Challenges of Implementing Evidence Based Practice: Ethical Considerations in Practice in Practice, Education, Policy and Research. Social Work and Society International Online Journal, 7(2). Available at www.socwork.net/sws/article/view/76/335 [Retrieved on 2/07/2014].

Gallina, N. (2010). Conflict between Professional Ethics and Practice Demands: Social Workers' Perceptions. Social Work Values and Ethics, 7(2), fall 2010.

Gass, S. I. (2009). Ethical guidelines and codes in operational research. Omega, 37:1044-1050. 
Hoefer, R., Watson, L. \& Preble, K. (2013). A Mixed Methods Examination of Non-profit Board Chair Preferences in hiring Executive Directors. Administration in Social Work, 37: 437-446.

Hopkins, K. M., Mudrick, N. R. \& Rudolph, C. S. (1999). Impact of university/agency partnership in child welfare organisations, workers and work activities. Child Welfare, 28 (6):749-773.

John, A., \& Crockwell, L. (2009). Reflecting on the Use of the Code of Ethics in Social Work Practice: A Newfoundland and Labrador Perspectives. Journal of Social Work Value and Ethics, 6 (2).

$\mathrm{Kim}, \mathrm{H}$. (2011). Job conditions, unmet expectations and burnout in public child welfare workers: How different from other social workers? Children and Youth Services Review, 33(2):358-367.

Kim, H. \& Lee, S. Y. (2009). Supervisory communication, burnout and turnover intention among social workers in health care settings. Social Work in Health Care, 48(4): 364-385.

Kugelman, W. (1992). Social Work Ethics in the practice arena: A qualitative study. Social Work in Health Care, 17 (4): 59-80.

Madden, E. E., Scannapieco, M., \& Painter, K. (2014). An examination of retention and length of employment among public child welfare workers. Children and Youth Services Review, 41:37-44.

Mason, S., LaPorte, H.H., Bronstein, L. R., \& Aurebach, C. (2012). Child welfare workers' perceptions of the value of social work education. Children and Youth Services Review, 34 (9):1735-1741.

Mason, J. (1996). Qualitative researching. London: Sage.

Millstein, K. (2000). Confidentiality in direct Social-Work practice: Inevitable challenges and ethical dilemmas. Families in Society: The Journal of Contemporary Human Services, 81 (3):270-282.

Moran, J., Frans, D., \& Gibson, P. (1995). A comparison of beginning MSW and MBA students on their aptitudes for human service management. Journal of Social Work Education, 31 (1): 95-105.

Mor Barak, M. E., Levin, A., Nissly, J. A., \& Lane, C. J. (2006). Why do they leave? Modelling child welfare workers' turnover intentions. Children and Youth Services Review, 28:548-577.

Patton, M. Q. (2002). Qualitative research and evaluation methods. (3rd ed.) Thousand Oaks, CA: Sage.

Quinn, R. E., Hildebrandt, H. W., Rogers, P. S. \& Thompson, M. P. (1991). A Competing Values Framework for Analysis Presentational Communication in Management Context. Journal of Business Communication, 28 (3): 213-232.

Reamer, F. G. (2001). Ethics education in social work. Alexandria, VA: Council on Social Work Education.

Reamer, F. G. (2005). Ethical and Legal Standards in Social Work: Consistency and Conflict. Families in Society, 86:163-69.

Reamer, F. G. (2013). Social work in a digital age: ethical and risk management challenges. Social work, 58 (2):163-172.

Reamer, F. G., \& Shardlow, S. M. (2009). Ethical codes of practice in the US and UK: one profession two standards. Journal of Social Work Values and Ethics, 6(2).

Richter, M.S. \& Mlambo, G.T. (2005). Perceptions of rural teenagers on teen pregnancy. Health SA Gesondheid. Vol 10, No 2. Available at www.thefreelibrary.com > ... > Health SA Gesondheid > June 1, 2005. [Retrieved on 17/08/2013].

Rodgers, J. A. (2009). Global Social Work Practice, Human Rights, Social Work Ethics and Human Responsibilities: The Challenge. Global Social Work Practice, Vol 2, Nos 2. Available at http://www.globalsocialwork.org [Accessed on 14/07/2014].

Scannapieco, M., Hegar, R. L., \& Connell-Carrick, K. (2012). Professionalisation in public child welfare: Historical context and workplace outcomes for social workers and non-social workers. Children and Youth Services Review, 34: 2170-2178.

Shim, M. (2010). Factors influencing child welfare employee's turnover: Focusing on organisational culture and climate. Children and Youth Services Review, 32 (10):847-856.

Stevens, B. (1996). Using the competing values framework to assess corporate ethical. Journal of Business Communication, 33(1): 7183.

Stoesen, L. (2006). Ensuring ethical practice: An examination of NASW Code violations, 1986- 97. Social Work, 45: 251-261.

South African Council of Social Service Practitioners (SACSSP, 2005). Policy Guidelines for Course of Conduct, Code of Ethics and the Rules for Social Workers. Available at http://www.sacssp.co.za/ [Retrieved on 27/07/2013].

Tartakorsky, E. \& Kovardinaky, S. (2013). Therapeutic orientations, professional efficacy and burnout among substance abuse social workers in Israel. Journal of Substance Abuse Treatment, 45:91-98.

Ulrich, C., O'Donnell, P., Taylor, C., Farrar, A., Danis, M. \& Crady, C. (2007). Ethical climate, ethics stress and job satisfaction of nurses and social workers in the United States. Social Science \& Medicine, 65:1708-1719.

Vandervort, F. E., Gonzalez, R. P. \& Faller, K. C. (2007). Legal ethics and high child welfare worker turnover: An unexplored connection. Children and Youth Services Review, 30 (5):546-563.

Veldsman, T. (2012). Organisational design as a critical organisational discipline. International Journal of Psychology, 47:546-547.

Weaver, D., Chang, J., Clark, S., \& Rhee, S. (2007). Keeping child welfare workers on the job. Administration in Social Work, 3(2):5-25.

Wendt, S., Cheers, B., Francis, K., Lonne, B., \& Schiller, W. (2011). Exploring Social Workers' personal domains in rural practice. Journal of Social Work, 1-17. Doi: 10.1177/1468017310382323. 